Hughes Elizabeth (Orcid ID: 0000-0002-4377-5610)

Accurso Erin (Orcid ID: 0000-0002-5521-6381)

Title:

Predictors of early response in conjoint and separated models of family-

based treatment for adolescent anorexia nervosa

Running title: Early response to FBT for anorexia

Authors \& Affiliations:

Elizabeth K. Hughes ${ }^{\text {a,b }}$

Susan M. Sawyer ${ }^{\mathrm{a}, \mathrm{b}, \mathrm{c}}$

Erin C. Accurso ${ }^{\mathrm{d}}$

Simar Singh ${ }^{\mathrm{d}}$

Daniel Le Grange $e^{\mathrm{d}, \mathrm{e}}$

a. Department of Paediatrics, University of Melbourne, Australia

b. Centre for Adolescent Health, Murdoch Children's Research Institute, Melbourne,

Australia

c. Centre for Adolescent Health and Department of Adolescent Medicine, Royal

Children's Hospital, Melbourne, Australia

d. Department of Psychiatry, University of California, San Francisco, UCSF Weill Institute for Neurosciences, San Francisco, CA, USA

e. Department of Psychiatry and Behavioral Neuroscience, The University of Chicago, IL, USA (Emeritus).

Correspondence to: Elizabeth K. Hughes (ORCID iD 000-0002-4377-5610)

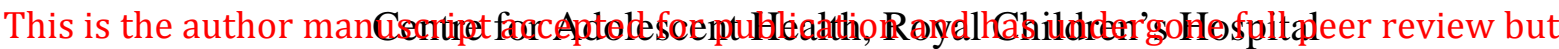
has not been through the copyediting, typesetting, pagination and proofreading process, which

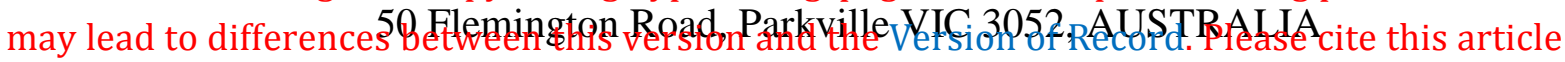
as doi: 10.1002/erv.2668

Phone: +61 39345 4738, Email: Libby.Hughes@rch.org.au

This article is protected by copyright. All rights reserved. 
Acknowledgements: The authors thank the Royal Children's Hospital Specialist Eating Disorder Program staff, patients and families.

Conflict of Interest: Daniel Le Grange receives royalties from Guilford Press and Routledge, and is co-director of the Training Institute for Child and Adolescent Eating Disorders, LLC. The remaining authors have no conflicts of interest to declare.

Funding: This work was supported by the Baker Foundation (Australia) and the University of Melbourne. The Murdoch Children's Research Institute is supported by the Victorian Government's Operational Infrastructure Support Program. 


\title{
Predictors of early response in conjoint and separated models of family-based treatment for adolescent anorexia nervosa
}

\begin{abstract}
Objective: Early response, as indicated by early weight gain, in family-based treatment (FBT) for adolescent anorexia nervosa (AN) predicts remission at end-of-treatment. However, little is known about what factors contribute to early response. Further, no previous studies have examined early response to separated forms of FBT. Method: Data from a randomized clinical trial of conjoint FBT and separated FBT (parent-focused treatment; PFT) were analyzed to examine the timing and amount of early weight gain that predicted remission, and identify factors associated with early response. Results: Weight gain of at least $2.80 \mathrm{~kg}$ in FBT $(N=55)$ and $2.28 \mathrm{~kg}$ in PFT $(N=51)$, by session 5 , were the best predictors of remission at end-of-treatment. Early response in FBT was predicted by greater paternal therapeutic alliance and lower paternal criticism. Early response in PFT was predicted by less severe eating disorder symptoms and negative affect at baseline, lower maternal criticism, and greater adolescent therapeutic alliance. Conclusions: The results confirm that early weight gain is an important prognostic indicator in both conjoint FBT and PFT, and suggest that addressing negative emotion, parental criticism, and therapeutic alliance early in treatment could improve remission rates.
\end{abstract}

This article is protected by copyright. All rights reserved. 


\section{Highlights:}

- Weight gain by session 5 was the best predictor of remission at end of family-based treatment for adolescent anorexia nervosa

- Several factors predicted early weight gain including greater therapeutic alliance, lower parental criticism, less severe eating disorder symptoms and lower negative affect.

- Addressing these factors early in treatment has the potential to improve remission rates for adolescent anorexia nervosa.

\section{Keywords:}

Family therapy; anorexia nervosa; adolescents; prognosis; therapeutic alliance

This article is protected by copyright. All rights reserved. 
Eating disorders (EDs) are severe psychiatric conditions that significantly contribute to the global burden of disease (Erskine, Whiteford, \& Pike, 2016). Of particular concern, around one-third to one-half of individuals treated for an ED do not fully remit, and many go on to have long-lasting psychological and physical complications including increased risk of premature death (Steinhausen, 2009). A positive prognostic indicator is ED symptom relief in the earliest stages of treatment. Indeed, a recent review of 34 studies found that rapid improvement in behavioral symptoms, cognitions, and weight were robust predictors of positive outcome at end-of-treatment and follow-up (Linardon, Brennan, \& de la Piedad Garcia, 2016). While identification of factors that contribute to early treatment response represents an important opportunity for improving outcomes in people with EDs, existing research has failed to show strong support for any specific factors. As such, research aimed at identifying and targeting baseline and within-treatment factors that could impact early treatment response is a priority (Linardon et al., 2016).

One of the most well-researched treatments with regard to early response in EDs is family-based treatment (FBT) for adolescent anorexia nervosa (AN), wherein early response has been defined as early weight gain. FBT is an outpatient treatment of 6 to 12 months duration in which parents are empowered to take control of their child's eating and restore them to a healthy weight (Lock \& Le Grange, 2013). It has a strong evidence base (Lock, 2015) and is recommended as the first-line treatment for adolescents with AN (National Institute for Health and Care Excellence, 2017). Despite positive findings, clinical trials suggest that when remission is defined in terms of both weight and cognitive recovery (i.e., $\geq$ 95\% median body mass index $[\mathrm{mBMI}]$ and a score on the Eating Disorder Examination 
[(EDE; Fairburn \& Cooper, 1993) within 1 standard deviation [SD] of community norms), FBT only achieves full remission in around one-third of adolescents by end-of-treatment (Le Grange et al., 2016; Lock, Agras, Bryson, \& Kraemer, 2005; Madden et al., 2014). Given that adolescence is the peak period for the onset of AN (Herpertz-Dahlmann, 2015) and a critical period for physical and psychosocial development (Patton et al., 2016), it is imperative that research investments are made to improve treatments for adolescent AN.

Several studies confirm that weight gain during the first few weeks of FBT is a significant predictor of positive outcome. One of the earliest studies was a randomized clinical trial (RCT) that compared 6 and 12 month doses of FBT (Lock, Couturier, Bryson, \& Agras, 2006). This study found that adolescents who were remitted at 12 months (i.e., $\geq 95 \%$ $\mathrm{mBMI}$ and an EDE score within 2 SD of community norms) had significantly greater weight gain at weeks 2, 9 and 10. Similarly, in an open trial of FBT, weight gain at sessions 1, 3, and 4 significantly predicted weight restoration (i.e., $\geq 95 \% \mathrm{mBMI}$ ) after 12 months of treatment, with a gain of at least $2.88 \%$ in body weight by session 4 being the strongest predictor of weight restoration (Doyle, Le Grange, Loeb, Doyle, \& Crosby, 2010). Although these studies demonstrated the predictive value of early weight gain, neither study examined factors associated with early weight gain.

Two subsequent RCTs extended these findings by analyzing potential predictors of early weight gain. In both studies, remission was defined as achieving both weight and cognitive recovery (i.e., $\geq 95 \% \mathrm{mBMI}$ and an EDE score within $1 \mathrm{SD}$ of community norms). The first study compared FBT to adolescent-focused therapy (Le Grange, Accurso, Lock, Agras, \& Bryson, 2014). In this study, remission after 12 months of FBT was predicted by weight gain 
at sessions 3 through 8 , and adolescents with early response (i.e., $\geq 2.65 \mathrm{~kg}$ by session 3 ) were more likely to have parents with a lower level of education. The second study compared FBT after hospitalization for medical stabilization to FBT after hospitalization for weight restoration (Madden et al., 2015). In this study, remission at end-of-treatment was predicted by weight gain of at least $1.8 \mathrm{~kg}$ by session 4 in the combined sample, and at least $2.3 \mathrm{~kg}$ and $0.5 \mathrm{~kg}$ by session 4 in the medical stabilization and weight restoration arms, respectively. No differences were found in baseline characteristics between early responders and early nonresponders in that study.

Taken together, these studies confirm the importance of early weight gain in FBT; however, they have largely failed to identify clinically relevant factors that could be targeted to improve early response. This is likely to be at least in part due to the narrow range of factors examined. The baseline characteristics described by Le Grange et al. (2014) and Madden et al. (2015) included sex, age, ethnicity, weight, duration of illness, prior hospitalization, co-morbid psychiatric disorder, medication, EDE score, family structure and parent education. Expanding the scope of factors investigated could provide much greater insight into early response. This might include factors related to emotional and psychological functioning, family environment, and therapeutic alliance.

A promising advance in FBT for adolescent AN has been the development of separated models of treatment delivery. Although the standard format of FBT is to have the whole family attend treatment sessions with the therapist together, early studies suggested greater benefits for a separated model in which the therapist saw the adolescent and parents independently (Eisler et al., 2000; Le Grange, Eisler, Dare, \& Russell, 1992). Recently, this 
format was extended into parent-focused treatment (PFT), whereby the therapist sees only the parents and the adolescent is monitored by a nurse (Hughes, Sawyer, Loeb, \& Le Grange, 2015). In an RCT comparing PFT to standard conjoint FBT, $43 \%$ of adolescents who received PFT achieved full remission by end-of-treatment (i.e., $\geq 95 \% \mathrm{mBMI}$ and an EDE score within $1 \mathrm{SD}$ of community norms) compared to $22 \%$ of those who received conjoint FBT (Le Grange et al., 2016). Despite these encouraging findings, more than half of the adolescents did not achieve full remission by end-of-treatment, highlighting the importance of examining how to further improve treatment response in FBT.

To date, early response within separated forms of FBT has not been investigated. The current study therefore utilized data from a recent RCT (Le Grange et al., 2016) to examine early weight gain as a predictor of remission for adolescents who received either conjoint FBT or PFT. Unlike previous studies in which initial FBT treatment sessions were at weekly intervals, treatment in this RCT started with twice weekly sessions for the first two weeks for both FBT and PFT. As this intensified treatment was offered to support early weight gain, replication of findings with regard to FBT was also of interest to see whether this increased intensity shifted the timing or amount of early weight gain that was predictive of remission. Importantly, the broad range of standardized measures that were administered at baseline and throughout treatment in this RCT provided the opportunity to explore a comprehensive set of factors that could potentially contribute to early response. While some of these factors have been tested in previous studies, such as ED psychopathology, demographics, and BMI (Le Grange et al., 2014; Madden et al., 2015), several others were novel, such as adolescent negative affect and parental expressed emotion and early treatment characteristics (e.g., 
therapeutic alliance, parent attendance). These are factors which could not only help to identify who is at-risk of poor treatment response, but also could be targets for interventions to improve response. It was expected that participants who did not exhibit early response to FBT and PFT, as indicated by lack of early weight gain, would have poorer functioning on measures of psychopathology (i.e., ED symptoms, depression, affect) and other clinical features (i.e, weight, duration of illness, comorbidities), as well as family (i.e, parental expressed emotion, non-intact family) and treatment characteristics (i.e, expectations, therapeutic alliance, parent attendance, inpatient admissions).

\section{Method}

\section{Participants}

This study utilized data from a RCT comparing conjoint FBT and PFT. The sample comprised 106 adolescents with AN $(\mathrm{n}=82)$ or Eating Disorder Not Otherwise Specified-AN type 1 or $2(n=24)$, according to DSM-IV criteria (American Psychiatric Association, 2000). The adolescents were between 12 and 18 years old $(M=15.5, S D=1.50), 88 \%$ were female, 93\% were Australian-born, and 63\% resided in intact two-parent families.

The study was approved by the Royal Children's Hospital Human Research Ethics Committee and all participants provided written informed consent. Details of the RCT protocol, interventions, sample characteristics, and primary outcomes have been previously published (Hughes, Le Grange, Court, Yeo, Campbell, Allan, et al., 2014; Hughes et al., 2015; Le Grange et al., 2016). The treatment groups did not differ on any baseline characteristics (see Le Grange et al., 2016). 


\section{Measures}

Weight was recorded by the therapist at each treatment session with the adolescent wearing light clothing without shoes. At baseline (approximately 1 week before the first treatment session) and at end of treatment, a researcher measured height to the nearest $0.1 \mathrm{~cm}$ using a calibrated wall-mounted stadiometer, and weight while wearing a gown to the nearest $0.05 \mathrm{~kg}$ using calibrated digital scales. For adolescents who were hospitalized for medical instability prior to starting treatment, the length of stay and amount of weight gained during the admission were also recorded. Weight at discharge was used to calculate baseline weight and assess eligibility for inclusion in the RCT. Attendance by parents at each FBT session was recorded by the treating therapist.

The EDE (Fairburn \& Cooper, 1993) was administered to adolescents at baseline and at the end of treatment. This semi-structured interview gauges the severity of ED symptoms over the past 4 weeks and comprises four subscales: Restraint, Eating Concerns, Shape Concerns, and Weight Concerns. In addition, at baseline, the adolescent completed the interview version of the Yale-Brown-Cornell Eating Disorder Scale (YBCEDS; Mazure, Halmi, Sunday, Romano, \& Einhorn, 1994) to assess the presence and severity of obsessions and compulsions specific to eating and weight, the Children's Depression Inventory (CDI; Kovacs, 1992), and the Positive and Negative Affect Scale (PANAS; Watson \& Clark, 1994; Watson, Clark, \& Tellegen, 1988).

At the baseline assessment, mothers and fathers completed the Five Minute Speech Sample (FMSS; Magana, Goldstein, Karno, \& Miklowitz, 1986) to assess expressed emotion 
(EE). Trained researchers coded the recordings to classify parents as low, borderline or high in criticism and/or emotional over-involvement (EOI) with regard to the parent's relationship with the adolescent using the standardized system which codes for: Initial Comment, Critical Comments, Relationship, Dissatisfaction, Excessive Self-sacrificing and Overprotective Behavior, Excessive Praise, and Emotional Displays. In brief, high criticism is rated as present if the parent makes a negative Initial Comment (i.e., a negative comment about their child at the start of the sample), makes a Critical Comment about their child at any point during the sample, or describes a negative Relationship with their child. Borderline criticism is present if the parent expresses Dissatisfaction with their child. High EOI is present if the parent expresses Excessive Self-sacrificing and Overprotective Behavior, Excessive Praise, or Emotional Displays. Borderline EOI is present when only some of these behaviors are expressed. Although the validity of using ratings of dissatisfaction as borderline measures of criticism and using adult derived criteria of EOI as applicable to children and adolescents have been questioned by some authors (e.g., McCarty \& Weisz, 2002; Van Furth, Van Strien, Van Son, \& Van Engeland, 1993; Wamboldt, O' Connor, Wamboldt, Gavin, \& Klinnert, 2000), 2002), they were retained in this study given the exploratory nature of the study and that the FMSS has not previously been included in studies of early response. Parents also completed the Parents Versus Anorexia Scale (PVAN; Rhodes, Baillie, Brown, \& Madden, 2005), a 7-item measure of parental self-efficacy in FBT.

After the first treatment session, parents and adolescents each completed the Therapy Suitability and Patient Expectancy scale (TSPE; Zaitsoff, Doyle, Hoste, \& Le Grange, 2008) which is comprised of two questions: "How suitable do you think this therapy is for your 
problem?" and "How successful do you think therapy will be?" Each item is rated on an 11point scale $(0=$ Not at all, $10=$ Extremely $)$. After the third treatment session (week two), parents and adolescents each completed the Helping Relationship Questionnaire (HRQ; Luborsky, 1984). This is an 11-item measure of therapeutic alliance with total scores potentially ranging from -33 to +33 .

\section{Procedure}

The RCT took place at a multidisciplinary specialist ED program at a large pediatric hospital in Melbourne, Australia. Families were invited to participate in the RCT following an intake assessment completed as either an outpatient or inpatient, depending on the mode of presentation. The assessment comprised medical and psychiatric evaluations, together with standardized clinical measures as detailed above. Families were randomized to receive either conjoint FBT $(n=55)$ or PFT $(n=51)$.

\section{Interventions}

Conjoint FBT and PFT were provided by mental health clinicians who received specialized training in the interventions and participated in weekly clinical supervision. Conjoint FBT sessions followed the treatment manual (Lock \& Le Grange, 2013) whereby the therapist weighed the adolescent at the start of each session, and then met with the whole family together for a 50-minute session. In PFT (Hughes et al., 2015), the adolescent was seen alone by a nurse for 10-15 minutes, during which time the adolescent was weighed and engaged in brief supportive counseling. Following this, the therapist saw the parents alone for 
a 50-minute session. Conjoint FBT included an in-session family meal at Session 2, and siblings were encouraged to attend sessions. In PFT, there was no family meal and siblings did not attend sessions. The phases, goals, and core tenets as outlined in the FBT manual were otherwise the same between the two treatments.

A full dose of treatment comprised 18 sessions over 6 months in both FBT and PFT. Sessions were held twice a week in weeks 1 and 2; once per week in weeks 3 through 10; and once every 2 to 3 weeks thereafter. The mean number of sessions attended was 14.7 (SD = 4.5) for FBT and $14.6(\mathrm{SD}=5.2)$ for PFT. Nine participants $(16 \%)$ dropped out of FBT before completing more than 9 sessions (i.e., half the treatment dose), and 7 (14\%) dropped out of PFT. There were no significant differences between treatment groups in dose or dropout rate $(p>.05)$.

\section{Statistical Analysis}

All analyses were undertaken using IBM SPSS version 24. Receiver operating characteristic (ROC) analyses tested the associations between weight gain (i.e., difference in kilograms between baseline and sessions 1-10) and remission at end-of-treatment for each treatment type (i.e., FBT and PFT). Remission was defined as being $\geq 95 \% \mathrm{mBMI}$ and having an EDE Global Score within 1 SD of community norms. Percent mBMI was calculated from the $50^{\text {th }}$ percentile BMI relative to age and gender according to growth charts of the Centers for Disease Control (2000). The relationship between weight gain and remission was examined using the ROC area under the curve (AUC), and corresponding 95\% confidence intervals. In medical research, an AUC between 0.50 and 0.70 reflects low accuracy, an AUC 
between 0.70 and 0.90 reflects moderate accuracy, and an AUC greater than 0.90 reflects high accuracy (Fischer, Bachmann, \& Jaeschke, 2003). Weight cut-points were selected to achieve adequate and comparable sensitivity and specificity.

Each treatment group was divided into early responders and early non-responders using the weight cut-points determined from the ROC analyses. Early responders and early nonresponders were then compared on each measure using independent sample t-tests for continuous measures and $\chi^{2}$ tests for categorical measures. In addition to the standardized measures, groups were compared on the following demographic and clinical factors: age, sex, family structure, parent education, presenting \%mBMI, duration of illness, psychiatric comorbidity, self-harm/suicide risk, admission prior to FBT, inpatient weight gain, and parent attendance at sessions 1 and 2. As so few studies have examined such a comprehensive range of predictors, an inclusive alpha level of .05 was retained. Effect sizes were calculated using Cohen's d for continuous variables and Cramer's V for categorical variables. For Cohen's d, $0.2=$ small, $0.5=$ medium, and $0.8=$ large, while for Cramer's $\mathrm{V}, 0.1=$ small, $0.3=$ medium, and $0.5=$ large (Cohen, 1988).

\section{Results}

\section{Early Weight Gain and Remission}

The results of the ROC analyses for FBT and PFT are shown in Table 1. For adolescents who received FBT, weight gain at sessions 4, 5, 8, and 9 was significantly related to remission. The earliest significant predictor of remission was weight gain of at least 1.83 
kg by session 4 (AUC $=.728, p=.017 ; 44 \%$ met threshold $)$. The sensitivity and specificity of this cut-point were .58 and .60 , respectively. Weight gain of at least $2.80 \mathrm{~kg}$ by session 5 was the next significant predictor of remission $(\mathrm{AUC}=.724, \mathrm{p}=.020 ; 36 \%$ met threshold). This cut-point had increased sensitivity (.75) and specificity (.73) and was therefore selected as the cut-point for further analysis of FBT.

For adolescents who received PFT, weight gain at session 3 and sessions 5 through 10 was significantly related to remission. The earliest significant predictor of remission was weight gain of at least $1.43 \mathrm{~kg}$ by session 3 (AUC $=.695, \mathrm{p}=.022 ; 48.9 \%$ met threshold). The sensitivity and specificity of this cut-point were .59 and .60 , respectively. Weight gain of at least $2.28 \mathrm{~kg}$ by session 5 was the next significant predictor of remission (AUC $=.745, \mathrm{p}=$ $.004 ; 45 \%$ met threshold). This cut-point had increased sensitivity (.73) and specificity (.71) and was therefore selected as the cut-point for further analysis of PFT.

[Insert Table 1 here]

\section{Early Response in FBT}

Adolescents who received conjoint FBT were divided into early treatment responders and early non-responders. Based on the ROC analyses, early responders were those who gained at least $2.80 \mathrm{~kg}$ by session 5 of FBT $(\mathrm{n}=20 ; 36 \%)$. There were no significant differences between the groups in baseline demographic and clinical characteristics (Table 2); however, there were some significant differences between the groups on standardized measures (Table 3). Specifically, FBT early responders had fathers with significantly higher therapeutic alliance $(t[24]=2.71, p=.012$, Cohen's $d=1.28,95 \%$ CIs of difference -17.17 to 
-2.33), and lower criticism $\left(\chi^{2}[2, \mathrm{~N}=33]=6.96, p=.031\right.$; Cramer's $\left.\mathrm{V}=0.37\right)$ compared to early non-responders.

\section{Early Response in PFT}

Adolescents who received PFT were divided into early treatment responders and early non-responders. Early responders were those who gained at least $2.28 \mathrm{~kg}$ by session 5 of PFT $(\mathrm{n}=23 ; 45 \%)$. There were no significant differences between the groups in baseline demographic and clinical characteristics (Table 2); however, there were significant differences between the groups on standardized measures (Table 3).

PFT early responders reported lower scores on the EDE Restraint subscale, $(t(49)=2.24$, $p=.030$, Cohen's $\mathrm{d}=.63,95 \% \mathrm{CI}$ of difference $0.12-2.29)$, as well as less severe preoccupations $(t[44]=2.25, p=.030$, Cohen's $d=0.67,95 \%$ CI of difference $0.32-5.97)$ and rituals $(t[44]=2.86, p=.007$, Cohen's $d=0.85,95 \%$ CI of difference $1.17-6.80)$ about weight and eating on the YBCEDS. They also reported experiencing less negative affect on the PANAS $(t[37]=2.79, p=.044$, Cohen's $d=0.68,95 \%$ CI of difference $0.22-14.91)$. Mothers of PFT early responders were less likely to be rated high in criticism $\left(\chi^{2}[2, N=43]=\right.$ $6.06, p=.048$, Cramer's V $=0.37$ ). At session 1 , compared to early non-responders, PFT early responders were more optimistic about the potential success of treatment (TSPE Expectancy, $t[42]=-2.34, p=.024$, Cohen's $\mathrm{d}=.71,95 \% \mathrm{CI}$ of difference -3.43 to -0.25$)$, and at session 3 reported significantly stronger therapeutic alliance with their nurse (HRQ, $t[36]=-2.75, p=.009$, Cohen's $\mathrm{d}=0.88,95 \%$ CI of difference -17.75 to -2.69$)$. The percentage of fathers who attended both sessions 1 and 2 was higher for PFT early responders 
$\left(\chi^{2}[2, \mathrm{~N}=40]=4.68, p=.030\right.$, Cramer's $\left.\mathrm{V}=0.34\right)$. Mothers' attendance was not analyzed due to ceiling effects with $94 \%$ attending both session 1 and 2.

In regard to inpatient admission prior to treatment, PFT early responders were less likely to have been admitted than early non-responders $\left(\chi^{2}[2, \mathrm{~N}=51]=5.37,22 \%\right.$ vs. $54 \%, p$ $=.020$, Cramer's $\mathrm{V}=0.32$ ). Among all adolescents who were admitted prior to receiving PFT, early responders gained more weight $(M=5.41 \mathrm{~kg})$ than early non-responders $(M=3.56 \mathrm{~kg}$; $t[18]=-2.15, p=.046$, Cohen's $d=1.26,95 \%$ CI of difference -3.65 to -0.04 ) despite similar length of stay $(M=16.8$ days, $S D=11.3$ vs. $M=15.8$ days, $S D=10.4 ; t[18]=-0.18, p=$ .857 , Cohen's $d=0.09,95 \%$ CI of difference -12.5 to 10.5 ).

[Insert Tables 2 and 3 here]

\section{Discussion}

This study confirmed that early weight gain is a significant prognostic indicator of remission in both conjoint FBT and PFT, and identified several factors associated with early weight gain. Although replication is needed in larger samples, the findings point to factors which represent potential targets for improving early response and, in turn, outcomes of treatment for adolescents with AN. This is an important advancement given that FBT only achieves full remission (i.e., both weight and cognitive recovery) for around one-third of adolescents, and previous studies have largely failed to identify factors associated with early response. Furthermore, notwithstanding the potential impact on long-term outcomes, improving early response has the added benefit of accelerating the adolescent's return to 
physical health, as well as social and academic activities which are often significantly disrupted by the disorder.

The analyses undertaken in this and previous studies have provided weight gain cut-offs that best predict treatment outcome. In the present study, the best predictor of remission at end-of-treatment was weight gain by session 5 which, in this study, corresponded with week 3 of treatment. These findings are consistent with previous research reporting weight gain at weeks 2 to 4 of FBT was associated with remission (Doyle et al., 2010; Le Grange et al., 2014; Lock et al., 2006; Madden et al., 2015). Notably, the weight cut-off identified as the best predictor of remission in FBT in this study (i.e., $2.80 \mathrm{~kg}$ ) was only slightly higher than that reported by Le Grange et al. (2014) and Madden et al. (2015) in the medical stabilization arm (i.e., $2.65 \mathrm{~kg}$ and $2.3 \mathrm{~kg}$, respectively). The weight cut-off identified for PFT was somewhat lower than that for conjoint FBT (i.e., $2.38 \mathrm{~kg}$ ) but, of interest, was nearly identical to that reported by Madden et al. (2015). In addition to differences in how FBT was delivered (i.e., intensity of initial session and separate parent and adolescent sessions), some of the variation between studies is likely to be due to differences in remission rates and how remission was defined. For instance, in this RCT, along with two others (Le Grange et al., 2014; Madden et al., 2015) full remission was defined as having both weight $\geq 95 \% \mathrm{mBMI}$ and an EDE score within 1 SD of community norms. Using these criteria, remission rates ranged from $22 \%$ to $42 \%$. By comparison, Lock et al. (2006) defined remission as having both weight $\geq 95 \% \mathrm{mBMI}$ and an EDE score within 2 SD of community norms, while Doyle et al. (2010) defined remission with regard to weight only (i.e., >95\% mBMI). These studies reported remission rates of $68 \%$ and $48 \%$, respectively. 
Despite variation across studies, early weight gain cut-points are clinically useful for identifying adolescents at risk of poor outcome and have already shown promise for identifying at-risk adolescents and informing subsequent changes to improve outcomes of FBT. For example, a recent pilot RCT of 45 adolescents with AN showed that the addition of three intensive parental coaching sessions for families in which the adolescent had gained less than $2.3 \mathrm{~kg}$ by session 4, increased the likelihood of achieving weight restoration by the end of FBT (Lock et al., 2015). Such results are encouraging for clinicians and families, as they demonstrate that even when early progress is slow, interventions can be introduced to improve prognosis. Greater effort is needed, however, to develop a range of interventions and test their effectiveness in large clinical trials.

While the identification of adolescents who fail to gain weight early and subsequent adaptions to treatment are potentially effective means for improving outcomes, an alternative approach is to proactively identify those most likely to have poor early response and intervene from the start. This approach, however, requires knowledge of the factors that contribute to poor early response. In contrast to previous studies that have largely failed to identify any factors associated with early response (Le Grange et al., 2014; Madden et al., 2015), the current study broadened the scope of factors examined and, in turn, identified a range of both parent and adolescent factors which could be targeted to improve early response.

In conjoint FBT, early response was associated with a stronger therapeutic alliance between the father and therapist and less expression of criticism toward the adolescent by their father. Fathers' attendance at the first two treatment sessions also predicted early 
response in PFT. In previous research, we have shown that greater attendance by fathers predicts better patient outcomes (Hughes, Burton, Le Grange, \& Sawyer, in press). This may be in part due to fathers' involvement contributing to greater relational containment whereby treatment enhances parental confidence and the parent-child relationship, leading the adolescent to feel more secure and to engage more readily in the therapeutic process (Wallis et al., 2017). Taken together, the results suggest that the father's relationships with their child and the therapist, as well as his participation in treatment, can have a significant impact on treatment progress. For clinicians, this highlights the importance of actively engaging fathers, building therapeutic rapport, and addressing any difficulties fathers may experience in relating to their ill child.

Likewise, mothers were also important to early treatment response, with early weight gain in PFT associated with mothers who were less critical of their child. These results suggest that addressing maternal criticism at the start of treatment might be helpful in improving early response. Of interest, previous studies have shown that adolescents whose mothers express high levels of criticism are more likely to have better outcomes in separated forms of FBT than those in conjoint FBT (Eisler et al., 2000), and that separated forms of FBT are associated with a decrease in maternal criticism (Allan, Le Grange, Sawyer, McLean, \& Hughes, 2018; Le Grange et al., 1992). Clearly more research is need to understand the interplay between parent criticism and treatments for adolescent AN including alternative models of FBT.

Notably, several adolescent factors were associated with early response in PFT. These included less severe dietary restraint, lower ED-related obsessions and compulsions, and 
lower negative affect. The findings regarding ED symptom severity are perhaps to be expected, given that previous research suggests that adolescents with high symptom severity, as measured by the EDE and YBCEDS, have poorer outcomes when they receive PFT (Le Grange et al., 2016) or adolescent-focused therapy (Le Grange et al., 2012) compared to conjoint FBT. However, this is the first study to show associations with early treatment response. The findings regarding negative affect are also new, but converge with research on emotion regulation difficulties associated with $\mathrm{AN}$ and the potential for treatments to target these difficulties (Haynos \& Fruzzetti, 2011). It should be noted, however, that the adolescent factors identified in this study were associated with early response in PFT, but not FBT. This may be due to the fact that in PFT the adolescent is not seen by the therapist directly. This could mean that when these difficulties are present, they are not as readily addressed and may be more likely to interfere with early progress. That said, negative affect was not found to moderate treatment outcomes in the main RCT analyses (Le Grange et al., 2016).

In addition to baseline factors, the adolescent's attitude towards treatment and their relationship with the nurse were associated with early weight gain in PFT. Specifically, adolescents who had early treatment response reported greater optimism at session 1 regarding the potential success of treatment and had a stronger therapeutic alliance with the nurse by session 3. Given that these factors were not associated with response in FBT, the results suggest the adolescent attitudes towards treatment are of greater significance in PFT. In some ways this may seem surprising, as the nurse only spends up to 15 minutes with the adolescent at each session to assess weight and vital signs, and provide brief supportive counseling. Rather than the seemingly neutral role this might suggest, it may in fact be an 
important opportunity for the adolescent to develop a supportive, therapeutic relationship which may be an important aspect of recovery. Further examination of the nurse role is warranted to explore the active components of this relatively brief intervention.

The findings regarding hospitalization prior to outpatient treatment are of particular interest given that this has not been previously examined. At this service, adolescents are admitted if they are medically unstable and are discharged once they are medically stable (Hughes, Le Grange, Court, Yeo, Campbell, Whitelaw, et al., 2014). This study showed that early non-responders in PFT were more likely to have been admitted to hospital prior to starting outpatient treatment. There are several possible explanations for this finding, including that the illness may be more severe and therefore recovery more protracted, or that the experience of hospitalization impacts negatively on the adolescent or parents (e.g., by reducing confidence or motivation). Alternatively, it could be argued that weight gain in the hospital contributes to reduced weight gain early in treatment. However, among all adolescents who were admitted to hospital (i.e., both early responders and early nonresponders) those who did not respond early to PFT gained less weight while in hospital, despite a similar length of stay to those who did respond. This suggests that it is not admission alone that is an indicator of risk for slow treatment response, but admission combined with low weight gain in hospital. Low weight gain in hospital may reflect low engagement in the treatment process by the adolescent, and could also impact on the family's sense of hope for recovery. As such, it may be that greater emphasis should be placed on strategies for achieving inpatient weight gain, including addressing the factors that may impede this, in addition to medical stability. 


\section{Strengths and Limitations}

The current study had several strengths that make it well placed to contribute to current knowledge and guide future research. The use of standardized assessments which are widely used in clinical and research settings speaks to the reliability and validity of the findings and the application of these measures in other services and future studies. The comprehensive range of characteristics examined broadened the scope of research, thus allowed for multiple factors to be identified which provide a promising focus for future research. The only previous study of FBT to find a significant factor reported that early response was associated with lower parent education (Le Grange et al., 2014), a factor which was not significant in the current study. Another strength is the similarity in findings to prior studies regarding the timing and amount of weight gain associated with remission, suggesting a high level of confidence in this finding. Finally, the study also demonstrated that lack of early weight gain as a marker of risk for poor outcome can be extended to a separated form of FBT, namely PFT.

Despite these strengths, there were also limitations to the study. The sample was relatively small when all combinations of treatment type, response category, and predictors were considered. Replication using larger samples is therefore needed to confirm the robustness of the findings. A large sample would also allow for cross-treatment comparisons of the factors that are differentially associated with early response. The results of the ROC analysis, although significant, gave AUC values which indicated moderate accuracy with regard to prediction of remission from early weight gain. This suggests that some participants 
classified as non-early responders, were remitted at end of treatment. However, the intention is to identify participants "at-risk" of not responding to treatment and it is unlikely that any test would achieve this with the highest degree of accuracy. Unlike medical diagnostic tests wherein accuracy is expected to be much higher (i.e., > .90), there are no accepted criteria in psychology and psychiatry and AUCs are generally much lower. Of note, the AUCs in the current study (.724 and .745) are slightly higher than those reported previously by Doyle et al. (2010) and Le Grange et al. (2014), who reported AUCs of .674 and .670, respectively. In addition, adjustment for multiple statistical comparisons was not made. As so few studies have examined such a comprehensive range of factors in relation to early response, an inclusive significance level was deemed appropriate; however, this approach increased the chance of type I error. Therefore, further investigation into the predictive validity of the factors highlighted by this study is encouraged.

\section{Conclusions}

In sum, this study represents a significant advancement in research on the importance of early treatment response by identifying several potential targets for improving early response and, in turn, outcomes for adolescents with AN. Many of the factors identified were of particular relevance to PFT which has already demonstrated promise as an efficacious alternative to conjoint FBT (Le Grange et al., 2016). The next steps will be to examine how the factors identified in this study can be modified and to test the impact of modification on early response and outcome. 


\section{References}

Allan, E., Le Grange, D., Sawyer, S. M., McLean, L. A., \& Hughes, E. K. (2018). Parental expressed emotion during two forms of family-based treatment for adolescent anorexia nervosa. European Eating Disorders Review, 26, 46-52. doi: 10.1002/erv.2564

American Psychiatric Association. (2000). Diagnostic and statistical manual of mental disorders (4th ed., text revision). Washington DC: American Psychiatric Press.

Centers for Disease Control and Prevention. (2000). Clinical Growth Charts.

Cohen, J. (1988). Statistical power analysis for the behavioral sciences (2nd ed.). Hillsdale, N.J.: Lawrence Erlbaum Associates, Inc.

Doyle, P. M., Le Grange, D., Loeb, K., Doyle, A. C., \& Crosby, R. D. (2010). Early response to family-based treatment for adolescent anorexia nervosa. International Journal of Eating Disorders, 43, 659-662. doi: 10.1002/eat.20764

Eisler, I., Dare, C., Hodes, M., Russell, G. F. M., Dodge, E., \& Le Grange, D. (2000). Family therapy for adolescent anorexia nervosa: The results of a controlled comparison of two family interventions. Journal of Child Psychology \& Psychiatry \& Allied Disciplines, 41, 727-736. doi: 10.1111/1469-7610.00660

Erskine, H. E., Whiteford, H. A., \& Pike, K. M. (2016). The global burden of eating disorders. Current Opinion in Psychiatry, 29, 346-353. doi:

10.1097/YCO.0000000000000276

This article is protected by copyright. All rights reserved. 
Fairburn, C. G., \& Cooper, Z. (1993). The Eating Disorder Examination (Twelfth Edition). In C. G. Fairburn \& G. T. Wilson (Eds.), Binge eating: Nature, assessment and treatment (pp. 317-360). New York, NY: The Guilford Press.

Fischer, J. E., Bachmann, L. M., \& Jaeschke, R. (2003). A readers' guide to the interpretation of diagnostic test properties: clinical example of sepsis. Intensive Care Med, 29, 1043-1051. doi: 10.1007/s00134-003-1761-8

Haynos, A. F., \& Fruzzetti, A. E. (2011). Anorexia nervosa as a disorder of emotion dysregulation: Evidence and treatment implications. Clinical Psychology: Science and Practice, 18, 183-202. doi: 10.1111/j.1468-2850.2011.01250.x

Herpertz-Dahlmann, B. (2015). Adolescent eating disorders: Update on definitions, symptomatology, epidemiology, and comorbidity. Child and Adolescent Psychiatric Clinics of North America, 24, 177-196. doi: 10.1016/j.chc.2014.08.003

Hughes, E. K., Burton, C., Le Grange, D., \& Sawyer, S. M. (in press). The participation of mothers, fathers, and siblings in family-based treatment for adolescent anorexia nervosa. . Journal of Clinical Child and Adolescent Psychology. doi: $10.1080 / 15374416.2017 .1390756$

Hughes, E. K., Le Grange, D., Court, A., Yeo, M., Campbell, S., Allan, E., . . Sawyer, S. M. (2014). Parent-focused treatment for adolescent anorexia nervosa: A study protocol of a randomised controlled trial. BMC Psychiatry, 14, 105. doi: 10.1186/1471-244X-14105

Hughes, E. K., Le Grange, D., Court, A., Yeo, M., Campbell, S., Whitelaw, M., . . Sawyer, S. M. (2014). Implementation of family-based treatment for adolescents with anorexia

This article is protected by copyright. All rights reserved. 
nervosa. Journal of Pediatric Health Care, 28, 322-330. doi:

10.1016/j.pedhc.2013.07.012

Hughes, E. K., Sawyer, S. M., Loeb, K. L., \& Le Grange, D. (2015). Parent-focused treatment. In K. L. Loeb, D. Le Grange \& J. Lock (Eds.), Family therapy for adolescent eating and weight disorders: New applications (pp. 59-71). New York, NY: Routledge/Taylor \& Francis Group.

Kovacs, M. (1992). Children's Depression Inventory technical manual. Ontario, Canada: Multi-Health Systems.

Le Grange, D., Accurso, E. C., Lock, J., Agras, S., \& Bryson, S. W. (2014). Early weight gain predicts outcome in two treatments for adolescent anorexia nervosa. International Journal of Eating Disorders, 47, 134-129. doi: 10.1002/eat.22221

Le Grange, D., Eisler, I., Dare, C., \& Russell, G. F. (1992). Evaluation of family treatments in adolescent anorexia nervosa: A pilot study. International Journal of Eating Disorders, 12, 347-358. doi: 10.1002/1098-108X(199212)12:4<347::AIDEAT2260120402>3.0.CO;2-W

Le Grange, D., Hughes, E. K., Court, A., Yeo, M., Crosby, R., \& Sawyer, S. M. (2016). Randomized clinical trial of parent-focused treatment and family-based treatment for adolescent anorexia nervosa. Journal of the American Academy of Child and Adolescent Psychiatry, 55, 683-692. doi: 10.1016/j.jaac.2016.05.007

Le Grange, D., Lock, J., Agras, W. S., Moye, A., Bryson, S. W., Jo, B., \& Kraemer, H. C. (2012). Moderators and mediators of remission in family-based treatment and

This article is protected by copyright. All rights reserved. 
adolescent focused therapy for anorexia nervosa. Behaviour Research and Therapy, 50, 85-92. doi: 10.1016/j.brat.2011.11.003

Linardon, J., Brennan, L., \& de la Piedad Garcia, X. (2016). Rapid response to eating disorder treatment: A systematic review and meta-analysis. International Journal of Eating Disorders, n/a-n/a. doi: 10.1002/eat.22595

Lock, J. (2015). An update on evidence-based psychosocial treatments for eating disorders in children and adolescents. Journal of Clinical Child and Adolescent Psychology, 44, 707-721. doi: 10.1080/15374416.2014.971458

Lock, J., Agras, S., Bryson, S., \& Kraemer, H. (2005). A comparison of short- and long-term family therapy for adolescent anorexia nervosa. Journal of the American Academy of Child and Adolescent Psychiatry, 44, 632-639. doi:

10.1097/01.chi.0000161647.82775.0a

Lock, J., Couturier, J., Bryson, S., \& Agras, S. (2006). Predictors of dropout and remission in family therapy for adolescent anorexia nervosa in a randomized clinical trial. International Journal of Eating Disorders, 39, 639-647. doi: 10.1002/eat.20328

Lock, J., \& Le Grange, D. (2013). Treatment manual for anorexia nervosa: A family-based approach (2nd ed.). New York: Guilford Press.

Lock, J., Le Grange, D., Agras, W. S., Fitzpatrick, K. K., Jo, B., Accurso, E., . . Stainer, M. (2015). Can adaptive treatment improve outcomes in family-based therapy for adolescents with anorexia nervosa? Feasibility and treatment effects of a multi-site treatment study. Behavior Research and Therapy, 73, 90-95. doi:

10.1016/j.brat.2015.07.015

This article is protected by copyright. All rights reserved. 
Luborsky, P. (1984). Principles of psychoanalytic psychotherapy. New York: Basic Books.

Madden, S., Miskovic-Wheatley, J., Wallis, A., Kohn, M., Hay, P., \& Touyz, S. (2015). Early weight gain in family-based treatment predicts greater weight gain and remission at the end of treatment and remission at 12-month follow-up in for adolescent anorexia nervosa. International Journal of Eating Disorders, 48, 919-922. doi:

10.1002/eat.22414

Madden, S., Miskovic-Wheatley, J., Wallis, A., Kohn, M., Lock, J., Le Grange, D., . . . Touyz, S. (2014). A randomized controlled trial of in-patient treatment for anorexia nervosa in medically unstable adolescents. Psychological Medicine, 1-13. doi: $10.1017 / \mathrm{s} 0033291714001573$

Magana, A. B., Goldstein, M. J., Karno, M., \& Miklowitz, D. J. (1986). A brief method for assessing expressed emotion in relatives of psychiatric patients. Psychiatry Research, 17, 203-212. doi: 10.1016/0165-1781(86)90049-1

Mazure, C. M., Halmi, K. A., Sunday, S. R., Romano, S. J., \& Einhorn, A. M. (1994). The Yale-Brown-Cornell Eating Disorder Scale: Development, use, reliability and validity. Journal of Psychiatric Research, 28, 425-445. doi: 10.1016/00223956(94)90002-7

McCarty, C. A., \& Weisz, J. R. (2002). Correlates of expressed emotion in mothers of clinically-referred youth: an examination of the Five-Minute Speech Sample. Journal of Child Psychology and Psychiatry and Allied Disciplines, 43, 759-768. doi: $10.1111 / 1469-7610.00090$

This article is protected by copyright. All rights reserved. 
National Institute for Health and Care Excellence. (2017). Eating disorders: Recognition and treatment. London: NICE.

Patton, G. C., Sawyer, S. M., Santelli, J. S., Ross, D. A., Afifi, R., Allen, N. B., . . Viner, R. M. (2016). Our future: A Lancet commission on adolescent health and wellbeing. The Lancet, 387, 2423-2478. doi: 10.1016/S0140-6736(16)00579-1

Rhodes, P., Baillie, A., Brown, J., \& Madden, S. (2005). Parental efficacy in the family-based treatment of anorexia: Preliminary development of the Parents Versus Anorexia Scale (PVA). European Eating Disorders Review, 13, 399-405. doi: 10.1002/erv.661

Steinhausen, H.-C. (2009). Outcome of eating disorders. Child and Adolescent Psychiatric Clinics of North America, 18, 225-242. doi: 10.1016/j.chc.2008.07.013

Van Furth, E. F., Van Strien, D. C., Van Son, M. J., \& Van Engeland, H. (1993). The validity of the Five-Minute Speech Sample as an index of expressed emotion in parents of eating disorder patients. Journal of Child Psychology and Psychiatry, 34, 1253-1260. doi: 10.1111/j.1469-7610.1993.tb01786.x

Wallis, A., Rhodes, P., Dawson, L., Miskovic-Wheatley, J., Madden, S., \& Touyz, S. (2017). Relational containment: exploring the effect of family-based treatment for anorexia on familial relationships. J Eat Disord, 5, 27. doi: 10.1186/s40337-017-0156-0

Wamboldt, F. S., O' Connor, W., Wamboldt, M. Z., Gavin, L. A., \& Klinnert, M. D. (2000). The Five Minute Speech Sample in children with asthma: Deconstructing the construct of expressed emotion. Journal of Child Psychology and Psychiatry, 41, 887898. doi: 10.1111/1469-7610.00676

This article is protected by copyright. All rights reserved. 
Watson, D., \& Clark, L. A. (1994). Manual for the Positive and Negative Affect Schedule Expanded Form: The University of Iowa.

Watson, D., Clark, L. A., \& Tellegen, A. (1988). Development and validation of brief measures of Positive and Negative Affect: The PANAS Scales. Journal of Personality and Social Psychology, 54, 1063-1070. doi: 10.1037/0022-3514.54.6.1063

Zaitsoff, S. L., Doyle, A. C., Hoste, R. R., \& Le Grange, D. (2008). How do adolescents with bulimia nervosa rate the acceptability and therapeutic relationship in family-based treatment? International Journal of Eating Disorders, 41, 390-398. doi: 10.1002/eat.20515

This article is protected by copyright. All rights reserved. 
Table 1. ROC analysis of weight gain since baseline predicting remission at end of treatment

\begin{tabular}{|c|c|c|c|c|c|}
\hline & Session & AUC (95\% CI) & Significance & $\begin{array}{l}\text { Weight gain } \\
\text { cut-point }^{\mathrm{a}}\end{array}$ & $\begin{array}{l}\text { Sensitivity, } \\
\text { Specificity }\end{array}$ \\
\hline \multirow[t]{10}{*}{ FBT } & 1 & $.588(.399, .777)$ & .354 & 0.28 & $.50, .56$ \\
\hline & 2 & $.570(.385, .755)$ & .463 & 0.53 & $.53, .44$ \\
\hline & 3 & $.671(.492, .850)$ & .073 & 1.53 & $.58, .60$ \\
\hline & 4 & $.728(.566, .890)$ & .017 & 1.83 & $.58, .60$ \\
\hline & 5 & $.724(.562, .886)$ & .020 & 2.80 & $.75, .73$ \\
\hline & 6 & $.671(.498, .844)$ & .076 & 3.55 & $.67, .67$ \\
\hline & 7 & $.642(.459, .825)$ & .143 & 4.33 & $.67, .68$ \\
\hline & 8 & $.704(.523, .884)$ & .036 & 4.92 & $.67, .67$ \\
\hline & 9 & $.721(.560, .882)$ & .025 & 5.58 & $.67, .67$ \\
\hline & 10 & $.669(.499, .839)$ & .085 & 6.13 & $.67, .67$ \\
\hline \multirow[t]{10}{*}{ PFT } & 1 & $.598(.436, .760)$ & .247 & 0.68 & $.59, .58$ \\
\hline & 2 & $.614(.448, .780)$ & .179 & 1.20 & $.68, .69$ \\
\hline & 3 & $.695(.545, .846)$ & .022 & 1.43 & $.59, .60$ \\
\hline & 4 & $.646(.487, .805)$ & .086 & 1.90 & $.64, .64$ \\
\hline & 5 & $.745(.602, .888)$ & .004 & 2.28 & $.73, .71$ \\
\hline & 6 & $.739(.594, .884)$ & .006 & 3.50 & $.68, .71$ \\
\hline & 7 & $.752(.609, .895)$ & .003 & 4.05 & $.73, .71$ \\
\hline & 8 & $.767(.628, .906)$ & .002 & 5.05 & $.73, .71$ \\
\hline & 9 & $.743(.591, .895)$ & .006 & 4.98 & $.71, .70$ \\
\hline & 10 & $.743(.589, .897)$ & .006 & 5.45 & $.76, .74$ \\
\hline
\end{tabular}

Note. ${ }^{\mathrm{a}}$ Cut-point to achieve comparable sensitivity and specificity.

FBT $=$ family-based treatment, PFT $=$ parent-focused treatment.

This article is protected by copyright. All rights reserved. 
Table 2. Demographic and clinical characteristics at baseline of early responders and early non-responders for FBT and PFT

\begin{tabular}{lccccc}
\hline & \multicolumn{2}{c}{ FBT } & & \multicolumn{2}{c}{ PFT } \\
\cline { 2 - 3 } \cline { 5 - 6 } & Early & Early Non- & & Early & Early Non- \\
& Responders & responders & & Responders & responders \\
\hline $\mathrm{N}$ & 20 & 35 & & 23 & 28 \\
Age, years & $15.0(1.3)$ & $15.6(1.3)$ & & $15.5(1.7)$ & $15.8(1.6)$ \\
Female & $16(80.0 \%)$ & $33(94.3 \%)$ & & $18(78.3 \%)$ & $26(92.9 \%)$ \\
Intact family & $15(75.0 \%)$ & $19(54.3 \%)$ & & $12(52.2 \%)$ & $21(75.5 \%)$ \\
Born in Australia (adolescent) & $18(90.0 \%)$ & $33(94.3 \%)$ & & $23(100 \%)$ & $24(85.7 \%)$ \\
Born in Australia (parents) & $14(70.0 \%)$ & $21(60.0 \%)$ & & $18(78.3 \%)$ & $19(67.9 \%)$ \\
University degree (parents) & $9(45.0 \%)$ & $16(47.1 \%)$ & & $10(43.5 \%)$ & $11(42.3 \%)$ \\
\% median BMI & $82.1(3.9)$ & $80.6(6.8)$ & & $81.9(6.1)$ & $83.7(6.3)$ \\
Duration of illness, months & $9.8(5.4)$ & $11.7(11.1)$ & & $11.5(9.8)$ & $8.9(6.4)$ \\
Psychiatric co-morbidity & $9(45.0 \%)$ & $11(31.4 \%)$ & & $7(30.4 \%)$ & $12(42.9 \%)$
\end{tabular}




\begin{tabular}{|c|c|c|c|c|}
\hline & \multicolumn{2}{|c|}{ FBT } & \multicolumn{2}{|c|}{ PFT } \\
\hline & $\begin{array}{c}\text { Early } \\
\text { Responders }\end{array}$ & $\begin{array}{l}\text { Early Non- } \\
\text { responders }\end{array}$ & $\begin{array}{c}\text { Early } \\
\text { Responders }\end{array}$ & $\begin{array}{l}\text { Early Non- } \\
\text { responders }\end{array}$ \\
\hline Suicidal/self-harm risk & $3(15.0 \%)$ & $4(11.4 \%)$ & $3(13.0 \%)$ & $1(3.6 \%)$ \\
\hline
\end{tabular}

Note. No significant differences by group at $p<.05$. 
Table 3. Comparisons of early responders and early non-responders for FBT and PFT

\begin{tabular}{|c|c|c|c|c|c|c|}
\hline \multirow[b]{2}{*}{ Measure } & \multirow[b]{2}{*}{ Subscale } & \multirow[b]{2}{*}{ Reporter } & \multicolumn{2}{|c|}{ FBT } & \multicolumn{2}{|c|}{ PFT } \\
\hline & & & $\begin{array}{c}\text { Early } \\
\text { Responders }\end{array}$ & $\begin{array}{l}\text { Early Non- } \\
\text { responders }\end{array}$ & Early Responders & $\begin{array}{l}\text { Early Non- } \\
\text { responders }\end{array}$ \\
\hline $\mathrm{N}$ & & & 20 & 35 & 23 & 28 \\
\hline \multirow[t]{4}{*}{ EDE } & Restraint & Adolescent & $2.42(2.25)$ & $2.44(2.18)$ & $1.77(1.96)$ & $2.98(1.87)^{*}$ \\
\hline & Eating Concerns & Adolescent & $1.61(1.62)$ & $1.87(1.78)$ & $1.38(1.41)$ & $1.86(1.60)$ \\
\hline & Weight Concerns & Adolescent & $2.13(1.66)$ & $2.17(1.93)$ & $1.59(1.51)$ & $2.27(1.48)$ \\
\hline & Shape Concerns & Adolescent & $2.19(1.92)$ & $2.36(2.08)$ & $1.84(1.78)$ & $2.69(1.82)$ \\
\hline \multirow[t]{2}{*}{ YBCEDS } & Preoccupations & Adolescent & $8.00(4.07)$ & $6.27(4.98)$ & $5.33(4.71)$ & $8.48(4.76)^{*}$ \\
\hline & Rituals & Adolescent & $7.16(3.69)$ & $5.57(4.88)$ & $4.33(4.37)$ & $8.32(4.98)^{* *}$ \\
\hline CDI & Total & Adolescent & $19.15(12.23)$ & $17.88(9.27)$ & $13.28(9.88)$ & $20.46(12.72)$ \\
\hline \multirow[t]{2}{*}{ PANAS } & Negative Affect & Adolescent & $26.72(10.11)$ & $26.78(7.43)$ & $21.71(10.64)$ & $29.27(11.65)^{*}$ \\
\hline & Positive Affect & Adolescent & $24.33(6.34)$ & $25.82(7.63)$ & $26.83(9.79)$ & $24.04(8.55)$ \\
\hline \multirow[t]{3}{*}{ TSPE } & Suitability & Adolescent & $6.89(2.82)$ & $6.00(2.55)$ & $7.00(2.32)$ & $5.70(3.14)$ \\
\hline & Expectancy & Adolescent & $6.44(2.94)$ & $6.32(1.91)$ & $7.67(2.08)$ & $5.83(3.01)^{*}$ \\
\hline & Suitability & Mother & $8.28(1.45)$ & $8.14(1.99)$ & $8.22(1.86)$ & $8.53(1.33)$ \\
\hline
\end{tabular}




\begin{tabular}{|c|c|c|c|c|c|c|}
\hline \multirow[b]{2}{*}{ Measure } & \multirow[b]{2}{*}{ Subscale } & \multirow[b]{2}{*}{ Reporter } & \multicolumn{2}{|c|}{ FBT } & \multicolumn{2}{|c|}{ PFT } \\
\hline & & & $\begin{array}{c}\text { Early } \\
\text { Responders }\end{array}$ & $\begin{array}{l}\text { Early Non- } \\
\text { responders }\end{array}$ & Early Responders & $\begin{array}{l}\text { Early Non- } \\
\text { responders }\end{array}$ \\
\hline & Expectancy & Mother & $8.00(1.46)$ & $7.34(1.86)$ & $8.22(1.90)$ & $8.47(0.94)$ \\
\hline & Suitability & Father & $8.42(1.24)$ & $8.38(1.83)$ & $8.34(1.26)$ & $8.77(1.36)$ \\
\hline & Expectancy & Father & $7.58(2.31)$ & $8.14(1.49)$ & $8.19(1.33)$ & $8.08(1.55)$ \\
\hline \multirow[t]{2}{*}{ PVA } & Total & Mother & $18.83(4.23)$ & $19.73(3.67)$ & $19.59(2.81)$ & $19.57(3.13)$ \\
\hline & Total & Father & $19.55(4.84)$ & $18.88(3.09)$ & $18.72(2.85)$ & $19.06(4.01)$ \\
\hline \multirow[t]{3}{*}{ HRQ } & Total & Adolescent & $12.00(18.68)$ & $3.41(17.25)$ & $21.00(8.86)$ & $10.78(13.74)^{* *}$ \\
\hline & Total & Mother & $23.00(9.27)$ & $17.55(8.22)$ & $21.88(8.55)$ & $19.44(7.04)$ \\
\hline & Total & Father & $25.75(5.04)$ & $16.00(9.52)^{*}$ & $20.82(10.69)$ & $19.38(9.47)$ \\
\hline FMSS $^{\mathrm{a}}$ & Criticism & Mother & $\begin{array}{c}7(47 \%) ; 6 \\
(40 \%) ; 2(13 \%)\end{array}$ & $\begin{array}{c}18(58 \%) ; 6 \\
(19 \%) ; 7(23 \%)\end{array}$ & $\begin{array}{c}11(61 \%) ; 4 \\
(22 \%) ; 3(17 \%)\end{array}$ & $\begin{array}{c}6(24 \%) ; 10 \\
(40 \%) ; 9(36 \%)^{*}\end{array}$ \\
\hline & $\begin{array}{l}\text { Emotional } \\
\text { Overinvolvement }\end{array}$ & Mother & $\begin{array}{c}7(47 \%) ; 5 \\
(33 \%) ; 3(20 \%)\end{array}$ & $\begin{array}{c}13(42 \%) ; 7 \\
(23 \%) ; 11(35 \%)\end{array}$ & $\begin{array}{c}9(50 \%) ; 5 \\
(28 \%) ; 4(22 \%)\end{array}$ & $\begin{array}{c}10(40 \%) ; 9 \\
(36 \%) ; 6(24 \%)\end{array}$ \\
\hline & Criticism & Father & $\begin{array}{c}8(80 \%) ; 1 \\
(10 \%) ; 1(10 \%)\end{array}$ & $\begin{array}{c}7(30 \%) ; 10 \\
(44 \%) ; 6(26 \%)^{*}\end{array}$ & $\begin{array}{c}10(77 \%) ; 2 \\
(15 \%) ; 1(8 \%)\end{array}$ & $\begin{array}{c}10(59 \%) ; 4 \\
(23 \%) ; 3(18 \%)\end{array}$ \\
\hline
\end{tabular}




\begin{tabular}{|c|c|c|c|c|c|c|}
\hline \multirow[b]{2}{*}{ Measure } & \multirow[b]{2}{*}{ Subscale } & \multirow[b]{2}{*}{ Reporter } & \multicolumn{2}{|c|}{ FBT } & \multicolumn{2}{|c|}{ PFT } \\
\hline & & & $\begin{array}{c}\text { Early } \\
\text { Responders }\end{array}$ & $\begin{array}{l}\text { Early Non- } \\
\text { responders }\end{array}$ & Early Responders & $\begin{array}{l}\text { Early Non- } \\
\text { responders }\end{array}$ \\
\hline & Emotional & Father & $4(40 \%) ; 3$ & $13(54 \%) ; 3$ & $7(54 \%) ; 5$ & $13(76 \%) ; 3$ \\
\hline & Overinvolvement & & $(30 \%) ; 3(30 \%)$ & $(13 \%) ; 8(33 \%)$ & $(38 \%) ; 1(8 \%)$ & $(18 \%) ; 1(6 \%)$ \\
\hline \multirow{2}{*}{\multicolumn{2}{|c|}{$\begin{array}{l}\text { Parent attended Sessions } 1 \text { and } 2 \\
\text { Inpatient admission }\end{array}$}} & Father $^{\mathrm{b}}$ & $15(88 \%)$ & $22(79 \%)$ & $15(88 \%)$ & $13(57 \%)^{*}$ \\
\hline & & & $7(35 \%)$ & $16(46 \%)$ & $5(22 \%)$ & $22(54 \%)^{*}$ \\
\hline \multicolumn{3}{|c|}{ Inpatient weight gain } & $2.76(1.56)$ & $3.48(2.52)$ & $5.41(1.01)$ & $3.56(1.81)^{*}$ \\
\hline
\end{tabular}

Note. ${ }^{a}$ Percentages indicate the portion classified low, borderline, and high, respectively. ${ }^{b}$ Mothers' attendance not analyzed due to ceiling effect.

$\mathrm{EDE}=$ Eating Disorder Examination, FBT $=$ family-based treatment, FMSS $=$ Five Minute Speech Sample, HRQ = Helping Relationship

Questionnaire, PANAS = Positive and Negative Affect Scale, PFT = parent-focused treatment, PVA = Parent Versus Anorexia Scale, TSPE =

Therapy Suitability and Patient Expectancy scale, YBCEDS = Yale-Brown-Cornell Eating Disorder Scale.

$* p<.05, * * p<.01$. 
This article is protected by copyright. All rights reserved. 


\section{University Library}

\section{- M M N E R VA A gateway to Melbourne's research publications}

Minerva Access is the Institutional Repository of The University of Melbourne

Author/s:

Hughes, EK;Sawyer, SM;Accurso, EC;Singh, S;Le Grange, D

Title:

Predictors of early response in conjoint and separated models of family-based treatment for adolescent anorexia nervosa

Date:

2019-05-01

Citation:

Hughes, E. K., Sawyer, S. M., Accurso, E. C., Singh, S. \& Le Grange, D. (2019). Predictors of early response in conjoint and separated models of family-based treatment for adolescent anorexia nervosa. EUROPEAN EATING DISORDERS REVIEW, 27 (3), pp.283-294. https:// doi.org/10.1002/erv.2668.

Persistent Link:

http://hdl.handle.net/11343/285455 